\title{
Study of respiratory allergens and associated factors in patients with allergic rhinitis referring to Imam Ali clinic in Shahrekord
}

\author{
Mohammad Ali Zamani ${ }^{(\mathbb{D})}$, Monireh Alipour ${ }^{2}$, Ali Ahmadi ${ }^{3}$, Abolfazl Khoshde $^{\mathbf{l}^{*}}$ \\ ${ }^{1}$ Assistant Professor, Department of Immunology, Shahrekord University of Medical Sciences, Shahrekord, Iran \\ ${ }^{2}$ General Practitioner, Student Research Committee, Shahrekord University of Medical Sciences, Shahrekord, Iran \\ ${ }^{3}$ Associate Professor, Modeling in Health Research Center, Shahrekord University of Medical Sciences, Shahrekord, Iran \\ ${ }^{4}$ Professor, Department of Pediatric Infectious Disease,, Shahrekord University of Medical Sciences, Shahrekord, Iran
}

*Corresponding Author: Abolfazl Khoshdel, Clinical Biochemistry Research Center, Shahrekord University of Medical Sciences, Rahmatiyeh, Shahrekord, Iran, Phone/Fax: +98 3833338891, E-mail: a.khoshdel@skums.ac.ir

\begin{abstract}
Background and aims: Respiratory allergens cause several problems for people with allergic rhinitis and are considered as a global challenge. This disease is an IgE-mediated nasal inflammatory disease that is triggered by the contact of the allergen. Therefore, this study was conducted to investigate respiratory allergens and associated factors in patients with allergic rhinitis who referred to a clinic in Shahrekord located in the southwest of Iran.

Methods: In this cross-sectional study, 200 patients including 100 males and 100 females were enrolled using a convenience sampling technique. Diagnoses were made according to clinical symptoms and observation. In addition, the skin prick tests were used to detect the allergens. Finally, data were recorded and then analyzed by Stata.

Results: Based on the results, $73.5 \%, 70.5 \%, 46 \%$, and $43 \%$ of the patients were allergic to the following allergens including Dermatophagoid pteronyssinus, Dermatophagoides parinae, tree, and grass, respectively. Further, the mean height in the group with a positive and negative test for the inhaled allergens equaled $144.92 \pm 29.72$ and $131.65 \pm 30.93$, respectively, with a statistically significant difference $(P<0.05)$. However, the mean weight, age, and the time at the onset of the disease were not significantly different between the two groups $(P>0.05)$. Furthermore, the negative or positive reaction to the allergens failed to significantly differ with respect to gender, marital status, occupation, the county of residence, the area of residence, family size, and a family history of the disease $(P>0.05)$.

Conclusion: Allergic rhinitis is regarded as a common disorder among teenagers and young adults in this setting. Allergy to one or more respiratory allergens was found to be highly prevalent in patients with allergic rhinitis and the highest rate of allergy was observed to the mites, followed by tree and grass.

Keywords: Allergens; Allergic rhinitis; Respiratory system
\end{abstract}

Received: 3 September 2018, Accepted: 19 March 2019, ePublished: 24 June 2019

\section{Introduction}

An allergy refers to the excessive response of the immune system to a harmless substance (1). In addition, allergic rhinitis is one of the allergic reactions that develops in many people and causes a decline in the quality of life (2). Immune response plays a role in the incidence of allergic reaction by certain mechanisms such as the activation of $\mathrm{IgE}$ against the allergen and the production of certain cytokines such as interleukin (IL)-2, IL-3, IL-4, IL-5, IL13, IL-10, IFN $\gamma$, and M-CSF by T helper (h) 1 and Th2 that cause inflammation in the nasal mucosa and thus produce mucus and the symptoms of this disease $(3,4)$. The optimal clearance of different pathogen types encountered by the human body needs the selective activation of particular cellular and/or humoral immune responses. The coordination of the types of effector responses is directed by Th cells by producing types 1 and 2 (Th1 and Th 2 cellassociated) cytokines (5). Allergic rhinitis can be seasonal or perennial. Plant allergens such as grass and pollen are some of the agents of seasonal allergic rhinitis (6). Further, several examples of the agents of perennial allergic rhinitis include dust, active or passive smoking, indoor and outdoor fumes, microbes and parasites, animal proteins, dust mites, and roach $(6,7)$.

However, the etiology of the allergic rhinitis is still a controversial issue and the interaction effect between the environment and genetic factors is considered a key factor in the development of allergic reactions such as rhinitis and asthma. Other epidemiological factors can be involved in the development of allergic reactions and the increased prevalence of the rhinitis as well. For example, changes in lifestyle and industrialization are assumed to

(C) 2019 The Author(s); Published by Shahrekord University of Medical Sciences. This is an open-access article distributed under the terms of the Creative Commons Attribution License (http://creativecommons.org/licenses/by/4.0), which permits unrestricted use, distribution, and reproduction in any medium, provided the original work is properly cited. 
play a role in the rate of developing allergic reactions in recent decades (8). According to a study conducted in the southwest of Iran, the prevalence of asthma and allergic reactions has undergone an increasing trend and 60\% of the participants are found to suffer from respiratory allergen and asthma (9). During recent years, respiratory allergens have increased with human activities. Climatic changes and community industrialization are among the main causes of allergic diseases $(10,11)$. Besides, with the epidemiological recognition of the disease and the determination of the prevalence of respiratory allergens, an important step can be taken to promote preventative plans, diagnosis, and treatments for this disease and thus reduce the additional costs which are imposed on the health care system $(12,13)$. Accordingly, this study aimed to investigate respiratory allergens and related factors among patients with allergic rhinitis who referred to a clinic in Shahrekord in the southwest of Iran during 2016.

\section{Materials and Methods}

This cross-sectional study (with the ethical number of IR.SKUMS.REC.1395.136) was conducted on patients with allergic rhinitis referring to Imam Ali clinic of Shahrekord in 2016. The sample size was determined 132 according to a relevant formula and in inspiration of a previous study in which the prevalence of skin prick testing (SPT) was $63.02 \%$. Furthermore, 200 patients were enrolled using a convenience sampling method in order to increase the rigor of the study. Demographic data including age, weight, and height were recorded for each patient.

The inclusion criteria were the presence of the clinical symptoms of allergic rhinitis and at least three of these symptoms including sneezing, runny nose, itchy eyes and nose, as well as allergic rhinitis symptoms for longer than three days and, finally, suffering from the disease for at least four weeks. Moreover, suffering from underlying diseases, lacking sufficient data in the patient's medical file to complete the checklist, being under 2 years, taking an antihistamine and immune system inhibitors, suffering from cystic fibrosis, being under immunotherapy, and not volunteering to participate in the study were considered as the exclusion criteria.

SPT was used in addition to descriptions and clinical examinations in order to detect the allergens. The SPT is a suitable test to confirm the quick reaction to type 1 (Th1 cell-associated) allergy that indicates the specific IgE binding to the tissue representing atopy. Moreover, the SPT is convenient and safe and can be conducted on all patients including the children (14). To conduct the SPT, one drop of the allergen was placed on the forearm and upper arm, a small cutaneous scratch was made using the prick needle, and the reaction was compared with those to positive (histamine) and negative (normal saline) control 10 minutes later. The reaction was considered positive if the response was over $0 \mathrm{~mm}$ swelling or hive or redness over $15 \mathrm{~mm}$. Besides, the severity of the reaction to the allergens was measured according to Table 1 (15-17). Diameter over $3 \mathrm{~mm}$ was considered as a positive SPT result. Reaction to inhaled respiratory allergens such as shrubs, grass, trees, Dermatophagoides farinae, Dermatophagoid pteronyssinus, and the brunette was investigated as well and the obtained data were recorded in a checklist.

The data were analyzed by Stata with a 95\% confidence interval. To investigate whether the difference was significant or not, $t$ test and chi-square test, as well as the analysis of variance or its corresponding nonparametric test were used according to the distribution of the data.

\section{Results}

The mean age, the mean weight, the mean height of the participants, and the mean time at the onset of the disease were $19.87 \pm 14.61$ years, $48.28 \pm 26.12 \mathrm{~kg}, 142.60 \pm 30.28$ $\mathrm{cm}$, and $39.32 \pm 18.54$ months, respectively.

The most frequent symptom was the runny nose $(92 \%)$, followed by sneezing $(78.5 \%)$, itching $(74.5 \%)$, stuffy nose $(71 \%)$, coughing $(27 \%)$, redness $(8 \%)$, and watery eyes (8\%). The incidence of allergy to one or more allergens, $D$. pteronyssinus, $D$. farinae, tree, and the grass was $82.5 \%$, $73.5 \%, 70.5 \%, 46 \%$, and $43 \%$, respectively. The mean difference in the qualitative variables between the groups of a positive and negative test of the inhaled allergens is shown in Table 2. Based on the results, there was no significant difference in mean age, the time at the onset of the disease, and the weight between the two groups, but the mean height of the group with positive reaction to allergy was significantly higher than that of the group with a negative reaction to the allergen $(P=0.01)$. Regarding qualitative variables, negative or positive reaction to the allergen represented no significant difference in terms of gender, marital status, occupation, the county of living, the place of residence, family size, and the family history of the disease $(P>0.05)$.

Additionally, itching, coughing, eye redness, watery eyes, sneezing, phlegm accumulation, and runny nose were not significantly associated with the allergen test result $(P>0.05)$.

Data analysis demonstrated that positive and negative reaction to the mites was not statistically significant regarding gender $(P=0.5)$, occupation $(P=0.5)$, county $(P=0.8)$, the place of residence $(P=0.8)$, family history

Table 1. Measurement and Interpretation of Skin Prick Test Results

\begin{tabular}{ll}
\hline Wheal Diameter $(\mathbf{m m})$ & Degree \\
\hline$<3$ & 0 \\
$3-3.99$ & +1 \\
$4-5.99$ & +2 \\
$6-8.99$ & +3 \\
$\geq 9$ or pseudopodium & +4 \\
\hline
\end{tabular}


$(P=0.2)$, and family size $(P=0.9)$, while allergic reaction to $D$. farinae and marital status was significantly associated $(P=0.009)$, the results of which are provided in Table 2 .

Table 3 presents the data related to the comparison of response to tree and grass based on the qualitative variables. Based on the results, positive and negative reaction to grass and tree was not statistically significant for marital status, the place of residence, family history, and family size $(P>0.05)$.

As shown in Table 4, a positive or negative reaction to the mites, grass, and tree was significantly different for the height $(P<0.05)$. In addition, allergic reaction to $D$. farinae and tree significantly differed for weight and height $(P<0.05)$, whereas allergic reaction to $D$. pteronyssinus was significantly different only for the patients' height. Eventually, response to grass significantly varied respecting the onset of the disease and height $(P<0.05)$.

\section{Discussion}

The present study was performed to evaluate the incidence of respiratory allergens and associated factors in patients with allergic rhinitis. The results of the current study revealed that many $(82.5 \%)$ of the studied patients were allergic to different allergens and the highest rate of allergy was related to the mites $(70.5 \%-73.5 \%)$, followed by the tree $(46 \%)$ and grass $(43 \%)$. The findings of a study in Iran demonstrated that the highest allergy rate, according to the SPT, in patients with rhinitis belonged to two mites, namely, D. farinae and D. pteronyssinus, as well as the tree, Alternaria alternate, and roach (18). Further, another study reported that the prevalence of allergy was estimated at $85.6 \%$ among the patients with allergy referring to a hospital in the southwest of Iran. The highest allergy in the above-mentioned study was related to grass-based weed pollens and tree, and the mites were reported to be the most prevalent indoor allergens (19).

Similarly, based on the results of a study in the UAE, $71 \%$ of the patients with allergic rhinitis were sensitive to environmental allergens. Moreover, the findings demonstrated that $44 \%$ of the patients were sensitive to grass (20), which is consistent with the results of the current study. Bunnag et al showed that in the recent years, allergic rhinitis has increased by around three times in Thailand, and reported mites and grass as the most important agent of indoor and outdoor pollution, respectively (12).

According to the reports of a study in India, the prevalence of allergy was $28.7 \%$ and the highest rate of allergy was associated with dust (21). Furthermore, the findings of another study indicated that the incidence rate of allergy was age-dependent such that the highest rate of allergy to mites and trees was observed in individuals above 4 years. The rate of allergy to the trees was $56.4 \%$ and to the mites $56.8 \%$ in 10 to 12 -year age group (22). Moreover, the prevalence of allergy to the allergens was

Table 2. Comparison of responses to Dermatophagoides pteronyssinus and Dermatophagoides farinae according to qualitative variables

\begin{tabular}{|c|c|c|c|c|c|c|c|}
\hline \multirow{2}{*}{ Variable (N) } & & \multicolumn{2}{|c|}{ Dermatophagoides pteronyssinus } & \multirow{2}{*}{$P$ value } & \multicolumn{2}{|c|}{ Dermatophagoides farinae } & \multirow{2}{*}{$P$ Value } \\
\hline & & Negative & Positive & & Negative & Positive & \\
\hline \multirow{2}{*}{ Gender } & Male (100) & 27 & 73 & \multirow{2}{*}{0.8} & 30 & 70 & \multirow{2}{*}{0.9} \\
\hline & Female (100) & 26 & 74 & & 29 & 71 & \\
\hline \multirow{2}{*}{ Marital status } & Single (134) & 41 & 93 & \multirow{2}{*}{0.17} & 46 & 88 & \multirow{2}{*}{$0.009^{*}$} \\
\hline & Married (66) & 12 & 54 & & 13 & 53 & \\
\hline \multirow{5}{*}{ Occupation } & Laborer (6) & 0 & 6 & \multirow{5}{*}{0.06} & 0 & 6 & \multirow{5}{*}{0.13} \\
\hline & Employed (17) & 3 & 14 & & 2 & 15 & \\
\hline & Housewife (38) & 9 & 29 & & 10 & 28 & \\
\hline & Self-employed (20) & 4 & 16 & & 5 & 15 & \\
\hline & Unemployed (119) & 37 & 82 & & 42 & 77 & \\
\hline \multirow{6}{*}{ County } & Ardal (3) & 0 & 3 & \multirow{6}{*}{0.8} & 0 & 3 & \multirow{6}{*}{0.6} \\
\hline & Boroujen (12) & 3 & 9 & & 3 & 9 & \\
\hline & Shahrekord (134) & 40 & 123 & & 46 & 117 & \\
\hline & Farsan (20) & 9 & 10 & & 9 & 10 & \\
\hline & Lordegan (2) & 1 & 1 & & 1 & 1 & \\
\hline & Kouhrang (1) & 0 & 1 & & 0 & 1 & \\
\hline \multirow{2}{*}{ Place of residence } & City (165) & 42 & 123 & \multirow{2}{*}{0.097} & 47 & 118 & \multirow{2}{*}{0.7} \\
\hline & Village (34) & 11 & 24 & & 12 & 23 & \\
\hline \multirow{2}{*}{ Family history } & Positive (111) & 26 & 85 & \multirow{2}{*}{0.57} & 31 & 80 & \multirow{2}{*}{0.9} \\
\hline & Negative (89) & 27 & 62 & & 28 & 61 & \\
\hline \multirow{3}{*}{ Family size } & Small (13) & 3 & 10 & \multirow{3}{*}{0.8} & 4 & 9 & \multirow{3}{*}{0.76} \\
\hline & Average (165) & 45 & 120 & & 49 & 116 & \\
\hline & Large (22) & 5 & 17 & & 6 & 16 & \\
\hline
\end{tabular}


Table 3. Comparison of response to tree and grass according to qualitative variables

\begin{tabular}{|c|c|c|c|c|c|c|c|}
\hline \multirow{2}{*}{ Variable (N) } & & \multicolumn{2}{|l|}{ Tree } & \multirow{2}{*}{$P$ value } & \multicolumn{2}{|l|}{ Grass } & \multirow{2}{*}{$P$ value } \\
\hline & & Negative & Positive & & Negative & Positive & \\
\hline \multirow{2}{*}{ Gender } & Male (100) & 57 & 43 & \multirow{2}{*}{0.47} & 64 & 36 & \multirow{2}{*}{0.22} \\
\hline & Female (100) & 51 & 49 & & 50 & 50 & \\
\hline \multirow{2}{*}{ Marital status } & Single (134) & 74 & 60 & \multirow{2}{*}{0.54} & 80 & 54 & \multirow{2}{*}{0.70} \\
\hline & Married (66) & 34 & 32 & & 34 & 32 & \\
\hline \multirow{5}{*}{ Occupation } & Laborer (6) & 1 & 5 & \multirow{5}{*}{0.12} & 2 & 4 & \multirow{5}{*}{0.79} \\
\hline & Employed (17) & 10 & 7 & & 10 & 7 & \\
\hline & Housewife (38) & 21 & 17 & & 22 & 16 & \\
\hline & Self-employed (20) & 12 & 8 & & 11 & 9 & \\
\hline & Unemployed (119) & 64 & 55 & & 69 & 50 & \\
\hline \multirow{6}{*}{ County } & Ardal (3) & 2 & 1 & \multirow{6}{*}{0.56} & 2 & 1 & \multirow{6}{*}{0.73} \\
\hline & Boroujen (12) & 4 & 8 & & 5 & 7 & \\
\hline & Shahrekord (134) & 91 & 72 & & 96 & 67 & \\
\hline & Farsan (20) & 9 & 10 & & 10 & 9 & \\
\hline & Lordegan (2) & 1 & 1 & & 0 & 2 & \\
\hline & Kouhrang (1) & 1 & 0 & & 1 & 0 & \\
\hline \multirow{2}{*}{ Place of residence } & City (165) & 84 & 81 & \multirow{2}{*}{0.4} & 91 & 74 & \multirow{2}{*}{0.7} \\
\hline & Village (34) & 28 & 11 & & 22 & 12 & \\
\hline \multirow{2}{*}{ Family history } & Positive (111) & 57 & 74 & \multirow{2}{*}{0.58} & 59 & 52 & \multirow{2}{*}{0.3} \\
\hline & Negative (89) & 51 & 38 & & 55 & 34 & \\
\hline \multirow{3}{*}{ Family size } & Small (13) & 7 & 6 & \multirow{3}{*}{0.057} & 6 & 7 & \multirow{3}{*}{0.62} \\
\hline & Average (165) & 92 & 73 & & 98 & 67 & \\
\hline & Large (22) & 9 & 13 & & 10 & 12 & \\
\hline
\end{tabular}

Table 4. Comparison of response to the mites, tree, and grass according to quantitative variables

\begin{tabular}{|c|c|c|c|c|c|c|c|c|c|}
\hline Variable & & Age & $P$ value & Onset & $P$ value & Weight & $P$ value & Height & $P$ value \\
\hline \multirow{5}{*}{$\begin{array}{l}\text { Dermatophagoid } \\
\text { pteronyssinus }\end{array}$} & Negative & $16.43 \pm 15.46$ & \multirow{5}{*}{0.2} & $44.62 \pm 75.75$ & \multirow{5}{*}{0.6} & $40.59 \pm 27.35$ & \multirow{5}{*}{$0.03^{*}$} & $131.28 \pm 32.00$ & \multirow{5}{*}{$0.01^{*}$} \\
\hline & +1 & $21.04 \pm 13.10$ & & $35.27 \pm 34.86$ & & $51.86 \pm 34.86$ & & $149.13 \pm 26.37$ & \\
\hline & +2 & $19.74 \pm 15.03$ & & $31.33 \pm 42.01$ & & $46.47 \pm 42.01$ & & $141.95 \pm 29.54$ & \\
\hline & +3 & $22.66 \pm 13.79$ & & $44.75 \pm 37.49$ & & $55.80 \pm 49.37$ & & $150.35 \pm 28.45$ & \\
\hline & +4 & $21.33 \pm 13.07$ & & $40.66 \pm 43.42$ & & $52.00 \pm 43.42$ & & $153.16 \pm 29.08$ & \\
\hline \multirow{5}{*}{$\begin{array}{l}\text { Dermatophagoide } \\
\text { farina }\end{array}$} & Negative & $16.52 \pm 14.99$ & \multirow{5}{*}{0.1} & $40.20 \pm 67.56$ & \multirow{5}{*}{0.6} & $41.50 \pm 26.70$ & \multirow{5}{*}{0.08} & $133.47 \pm 31.19$ & \multirow{5}{*}{$0.04^{*}$} \\
\hline & +1 & $17.83 \pm 12.46$ & & $24.76 \pm 29.45$ & & $47.59 \pm 26.14$ & & $143.80 \pm 30.40$ & \\
\hline & +2 & $21.52 \pm 14.84$ & & $41.87 \pm 51.24$ & & $49.86 \pm 24.92$ & & $145.35 \pm 27.70$ & \\
\hline & +3 & $22.35 \pm 14.25$ & & $43.51 \pm 51.64$ & & $54.08 \pm 25.40$ & & $148.07 \pm 30.60$ & \\
\hline & +4 & $28.50 \pm 15.67$ & & $33.50 \pm 32.38$ & & $60.00 \pm 29.32$ & & $165.25 \pm 35.56$ & \\
\hline \multirow{5}{*}{ Tree } & Negative & $18.63 \pm 15.22$ & \multirow{5}{*}{0.2} & $35.18 \pm 26.18$ & \multirow{5}{*}{0.8} & $44.43 \pm 27.19$ & \multirow{5}{*}{$0.03^{*}$} & $137.39 \pm 30.58$ & \multirow{5}{*}{$0.003^{*}$} \\
\hline & +1 & $19.70 \pm 18.82$ & & $40.30 \pm 73.01$ & & $51.20 \pm 22.59$ & & $150.70 \pm 28.14$ & \\
\hline & +2 & $23.90 \pm 13.48$ & & $44.27 \pm 53.55$ & & $56.09 \pm 22.87$ & & $153.33 \pm 23.62$ & \\
\hline & +3 & $17.08 \pm 14.80$ & & $45.96 \pm 47.97$ & & $44.65 \pm 28.50$ & & $135.55 \pm 35.15$ & \\
\hline & +4 & $24.05 \pm 10.77$ & & $43.40 \pm 44.72$ & & $66.05 \pm 30.17$ & & $159.20 \pm 21.24$ & \\
\hline \multirow{5}{*}{ Grass } & Negative & $18.42 \pm 15.27$ & \multirow{5}{*}{0.4} & $36.03 \pm 57.82$ & \multirow{5}{*}{$0.02^{*}$} & $44.33 \pm 26.87 \pm$ & \multirow{5}{*}{0.05} & $136.89 \pm 30.19$ & \multirow{5}{*}{$0.03^{*}$} \\
\hline & +1 & $21.15 \pm 13.60$ & & $32.35 \pm 52.59$ & & $50.00 \pm 22.95$ & & $147.50 \pm 27.32$ & \\
\hline & +2 & $20.71 \pm 14.46$ & & $37.94 \pm 42.86$ & & $51.38 \pm 26.96$ & & $146.46 \pm 32.37$ & \\
\hline & +3 & $24.61 \pm 12.26$ & & $73.85 \pm 50.62$ & & $62.14 \pm 19.67$ & & $160.23 \pm 21.68$ & \\
\hline & +4 & $21.16 \pm 13.25$ & & $13.16 \pm 12.42$ & & $49.00 \pm 22.51$ & & $148.00 \pm 30.51$ & \\
\hline
\end{tabular}

Note. $* P<0.05$ is significant.

studied among the patients with allergic rhinitis in Nigeria by the SPT and it derived at most 35\% (23), which is lower compared to that of the current study. However, the result of this study demonstrated that the highest allergy rate was attributed to mites and tree-based allergens (23), which is in line with that of the present study. Al-Abri et al in Oman found that the prevalence of perennial rhinitis was higher than that of the seasonal rhinitis and perennial 
rhinitis antigen was related to the mites in $80 \%$ of the participants (13).

In the current study, the mean height in the group with a positive reaction to the allergen was significantly higher than that of the group with a negative reaction, and allergic reaction to $D$. farinae was significantly associated with marital status. Conversely, the mean age, the time at the onset of the disease, and the weight were not significantly different between the two groups.

Manco et al reported that the circulating levels of IL-6, leptin, and PCR reduced in morbidly obese women after bariatric surgery. However, adiponectin increased with a decrease in cardiovascular risk. In addition, no significant changes were observed in the circulating TNF- $\alpha$ or the levels of circulating mannose-binding lectin and bactericidal/permeability-increasing protein. Contrarily, significant changes were found in the levels of sCD14 and visfatin in patients who lost more than $20 \%$ of their initial body mass index (BMI). Further, $\alpha$-defensin levels significantly decreased after the bilio-pancreatic diversion. In the molecules of the innate immune system, there was a positive correlation between MBL and the whole-body glucose uptake before and after weight loss. Changes in sCD14 were significantly related to those changes in BMI and insulin sensitivity as well (24).

In another study, immunomodulatory factors, age, body fat, and free testosterone levels were controlled and reported while there was no association between body height and the studied immune parameters in both sexes (25).

The results of a study in China demonstrated that family history and the current place of residence were among the risk factors for allergic reaction in patients with rhinitis, but such association was not significant regarding age (26). Further, the development of allergic symptoms was not significant for gender, age group, and body mass index and such association was not significant for marital status as well (27). Sinha et al reported that occupation and family history were two independent risk factors for the incidence of allergic reactions in patients with rhinitis (28). A study in the United States investigated socioeconomic factors and showed that gender, age, race, and low age were significantly associated with increased IgE mediators (29).

Obviously, the trend of seasonal changes, geographical region (20), latitude and weather (30), industrialization, and genetic history (31) are among the determinants of distribution and the prevalence of respiratory allergens. The difference in these factors can explain the inconsistency in the prevalence of allergens in different regions of the world.

\section{Conclusion}

Based on the results, allergy to one or more respiratory allergens was highly prevalent in patients with rhinitis with the highest rate of allergy associated with the mites, trees, and grass, respectively. In this study, rhinitis was diagnosed only based on clinical criteria, while it was more appropriate to use the available standard questionnaires in this respect. Therefore, it is recommended to investigate other chemical pollutants such as seasonal variations, smoking, and pollutants from motor vehicles in future studies. Moreover, natural allergens such as roach and animal proteins should be studied comprehensively. Finally, it is advised to study food allergens as a stimulating factor alongside respiratory allergens.

Conflict of interests

None.

\section{References}

1. Janeway CA Jr, Travers P, Walport M, Shlomchik MJ. Immunobiology: the immune system in health and disease. 5th ed. New York: Garland Science; 2001.

2. Tran NP, Vickery J, Blaiss MS. Management of rhinitis: allergic and non-allergic. Allergy Asthma Immunol Res. 2011;3(3):14856. doi: 10.4168/aair.2011.3.3.148.

3. Packard KA, Khan MM. Effects of histamine on Th1/Th2 cytokine balance. Int Immunopharmacol. 2003;3(7):909-20. doi: 10.1016/s1567-5769(02)00235-7.

4. Min YG. The pathophysiology, diagnosis and treatment of allergic rhinitis. Allergy Asthma Immunol Res. 2010;2(2):6576. doi: 10.4168/aair.2010.2.2.65.

5. Kapsenberg ML, Hilkens CM, Wierenga EA, Kalinski P. The paradigm of type 1 and type 2 antigen-presenting cells. Implications for atopic allergy. Clin Exp Allergy. 1999;29 Suppl 2:33-6.

6. Small P, Kim H. Allergic rhinitis. Allergy Asthma Clin Immunol. 2011;7 Suppl 1:S3. doi: 10.1186/1710-1492-7-s1-s3.

7. Taborda-Barata L, Potter PC. Socio-epidemiological aspects of respiratory allergic diseases in Southern Africa. World Allergy Organ J. 2012;5(1):1-8. doi: 10.1097/ WOX.0b013e318242d6b4.

8. Zhang Y, Zhang L. Prevalence of allergic rhinitis in china. Allergy Asthma Immunol Res. 2014;6(2):105-13. doi: 10.4168/aair.2014.6.2.105.

9. Forouzan A, Masoumi K, Haddadzadeh Shoushtari M, Idani E, Tirandaz F, Feli M, etal. An overview of thunderstorm-associated asthma outbreak in southwest of Iran. J Environ Public Health. 2014;2014:504017.doi:10.1155/2014/504017.

10. D'Amato G, Vitale C, Lanza M, Molino A, D'Amato M. Climate change, air pollution, and allergic respiratory diseases: an update. Curr Opin Allergy Clin Immunol. 2016;16(5):434-40. doi: 10.1097/aci.0000000000000301.

11. Barne C, Alexis NE, Bernstein JA, Cohn JR, Demain JG, Horner $E$, et al. Climate change and our environment: the effect on respiratory and allergic disease. J Allergy Clin Immunol Pract. 2013;1(2):137-41. doi: 10.1016/j.jaip.2012.07.002.

12. Bunnag C, Jareoncharsri $P$, Tantilipikorn $P$, Vichyanond $P$, Pawankar R. Epidemiology and current status of allergic rhinitis and asthma in Thailand -- ARIA Asia-Pacific Workshop report. Asian Pac J Allergy Immunol. 2009;27(1):79-86.

13. Al-Abri R, Bharghava D, Kurien M, Chaly V, Al-Badaai $Y$, Bharghava K. Allergic rhinitis and associated comorbidities: prevalence in Oman with knowledge gaps in literature. Oman Med J. 2014;29(6):414-8. doi: 10.5001/omj.2014.111.

14. Chan EY, Dundas I, Bridge PD, Healy MJ, McKenzie SA. Skinprick testing as a diagnostic aid for childhood asthma. Pediatr Pulmonol. 2005;39(6):558-62. doi: 10.1002/ppul.20227.

15. Arshi S, Zarrinfard R, Fereshtehnejad SM, Poorsattar Bejeh Mir A, Javahertarash N. Determination of the prevalence of allergy 
to autumn pollens in allergic rhinitis patients referred to the immunology-allergy clinic of Hazrat Rasool-e-Akram Hospital in Tehran during 2005-06. Razi Journal of Medical Sciences. 2010;17(75):59-67.

16. Demoly P, Michel FB, Bousquet J. In Vivo Methods for Study of Allergy: Skin Tests, Techniques and Interpretation. New York: Mosby Co; 1998:430-9.

17. Adkinson NF Jr, Bochner BS, Burks AW, Busse WW, Holgate ST, Lemanske RF Jr, et al. Middleton's allergy: principles and practice. Philadelphia, PA: Elsevier Health Sciences; 2013.

18. Hosseini S, Shoormasti RS, Akramian R, Movahedi M, Gharagozlou M, Foroughi N, et al. Skin prick test reactivity to common aero and food allergens among children with allergy. Iran J Med Sci. 2014;39(1):29-35.

19. Assarehzadegan MA, Shakurnia A, Amini A. The most common aeroallergens in a tropical region in Southwestern Iran. World Allergy Organ J. 2013;6(1):7. doi: 10.1186/1939-4551-6-7.

20. Mahboub B, Al-Hammadi S, Prakash VP, Sulaiman N, Blaiss MS, Redha AA, et al. Prevalence and triggers of allergic rhinitis in the United Arab Emirates. World Allergy Organ J. 2014;7(1):19. doi: 10.1186/1939-4551-7-19.

21. Nitin J, Palagani R, Shradha NH, Vaibhav J, Kowshik K, Manoharan R, et al. Prevalence, severity and risk factors of allergic disorders among people in south India. Afr Health Sci. 2016;16(1):201-9. doi: 10.4314/ahs.v16i1.27.

22. Sheehan WJ, Rangsithienchai PA, Baxi SN, Gardynski A, Bharmanee A, Israel E, et al. Age-specific prevalence of outdoor and indoor aeroallergen sensitization in Boston. Clin Pediatr (Phila). 2010;49(6):579-85. doi: 10.1177/0009922809354326.

23. Ibekwe PU, Ibekwe TS. Skin prick test analysis in allergic rhinitis patients: a preliminary study in Abuja, Nigeria. J Allergy (Cairo). 2016;2016:3219104. doi: 10.1155/2016/3219104.

24. Manco M, Fernandez-Real JM, Equitani F, Vendrell J, Valera Mora ME, Nanni G, et al. Effect of massive weight loss on inflammatory adipocytokines and the innate immune system in morbidly obese women. J Clin Endocrinol Metab. 2007;92(2):483-90. doi: 10.1210/jc.2006-0960.

25. Pawlowski B, Nowak J, Borkowska B, Augustyniak D, DrulisKawa Z. Body height and immune efficacy: testing body stature as a signal of biological quality. Proc Biol Sci. 2017;284(1859). doi: 10.1098/rspb.2017.1372.

26. Li CW, Chen DD, Zhong JT, Lin ZB, Peng H, Lu HG, et al. Epidemiological characterization and risk factors of allergic rhinitis in the general population in Guangzhou City in china. PLoS One. 2014;9(12):e114950. doi: 10.1371/journal. pone.0114950.

27. Pefura-Yone EW, Kengne AP, Balkissou AD, Boulleys-Nana JR, Efe-de-Melingui NR, Ndjeutcheu-Moualeu PI, et al. Prevalence of asthma and allergic rhinitis among adults in Yaounde, Cameroon. PLoS One. 2015;10(4):e0123099. doi: 10.1371/journal.pone.0123099.

28. Sinha B, Singla R, Chowdhury R. Allergic rhinitis: a neglected disease - a community based assessment among adults in Delhi. J Postgrad Med. 2015;61(3):169-75. doi: 10.4103/00223859.159418.

29. Salo PM, Arbes SJ Jr, Jaramillo R, Calatroni A, Weir $\mathrm{CH}_{\text {, }}$ Sever $M L$, et al. Prevalence of allergic sensitization in the United States: results from the National Health and Nutrition Examination Survey (NHANES) 2005-2006. J Allergy Clin Immunol. 2014;134(2):350-9. doi: 10.1016/j. jaci.2013.12.1071.

30. Weiland SK, Husing A, Strachan DP, Rzehak P, Pearce N. Climate and the prevalence of symptoms of asthma, allergic rhinitis, and atopic eczema in children. Occup Environ Med. 2004;61(7):609-15. doi: 10.1136/oem.2002.006809.

31. Haydon RC 3rd. Addressing the prevalence of respiratory allergy in the home environment. Otolaryngol Clin North Am. 2003;36(5):803-24, vi. 